\title{
Modeling Impacts of Viticultural and Environmental Factors on 3-Isobutyl-2-Methoxypyrazine in Cabernet franc Grapes
}

\author{
Justin J. Scheiner, ${ }^{1}$ Justine E. Vanden Heuvel, ${ }^{2}$ Bruce Pan, ${ }^{3}$ \\ and Gavin L. Sacks**
}

\begin{abstract}
A study was conducted to determine the key environmental and viticultural variables affecting the concentration of 3-isobutyl-2-methoxypyrazine (IBMP) in Cabernet franc grapes. Berries were sampled from individual vines at 30 days after anthesis (DAA), 50 DAA, and harvest from 10 and 8 commercial New York State vineyards in 2008 and 2009, respectively. IBMP concentrations at 50 DAA were significantly higher in the warmer 2008 growing season $(2008,103$ to $239 \mathrm{pg} / \mathrm{g} ; 2009,12$ to $87 \mathrm{pg} / \mathrm{g})$. However, in the cooler 2009 growing season a smaller percent decrease in IBMP from 50 DAA to harvest was observed, so that IBMP at harvest was not significantly different between years $(2008,1$ to $13 \mathrm{pg} / \mathrm{g} ; 2009,5$ to $14 \mathrm{pg} / \mathrm{g})$. IBMP accumulation up to 50 DAA and log-fold decrease of IBMP from 50 DAA to harvest was modeled as a function of $>120$ viticultural and environmental variables (122 in 2008 and 140 in 2009). Important variables identified for modeling IBMP at 50 DAA were those associated with vine vigor, which was positively correlated with IBMP accumulation. Cluster light exposure did not explain differences in IBMP accumulation across sites, but it was important for modeling smaller differences within some sites. IBMP decrease could not be satisfactorily modeled across multiple sites, but within sites the decrease was most consistently correlated with classic fruit maturity indices (total soluble solids [TSS], TSS* $\mathrm{pH}^{2}$ ). The intensity of herbaceous aromas in wines produced from each site was not correlated with IBMP concentration, but multivariate models indicated that lower vine water status was the best predictor of increased herbaceousness.
\end{abstract}

Key words: IBMP, partial least squares regression, vigor, methoxypyrazines, modeling

The 3-alkyl-2-methoxypyrazines (MPs) are a class of odorants associated with herbaceous aromas of some Bordeaux winegrape (Vitis vinifera L.) cultivars (e.g., Cabernet franc, Merlot, Cabernet Sauvignon, Carménère, Sauvignon blanc). In grapes and wine, the MPs most often studied are 3-isobutyl-2-methoxypyrazine (IBMP), 3-isopropyl-2-methoxypyrazine (IPMP), and 3-sec-butyl-2-methoxypyrazine (sBMP). Quantitatively, IBMP is predominant and is typically present in concentrations an order of magnitude higher than IPMP and sBMP (Alberts et al. 2009).

In red wine, the sensory detection threshold of IBMP is reportedly 15 pg/mL (Roujou de Boubée et al. 2000). IBMP masks fruity aromas (Hein et al. 2009) and the positive correlation of IBMP with bell pepper aroma intensity is widely

${ }^{1}$ Graduate Student and ${ }^{2}$ Assistant Professor of Viticulture, Cornell University, Department of Horticulture, NYSAES, Geneva, NY 14456, and Plant Sciences Building, Ithaca, NY 14853, ${ }^{3}$ former Postdoctoral Scientist, E\&J Gallo Winery 600 Yosemite Ave Modesto, CA, 95353, and ${ }^{4}$ Assistant Professor of Enology, Cornell University, Department of Food Science, NYSAES, Geneva, NY 14456.

*Corresponding author (email: gls9@cornell.edu)

Acknowledgments: The authors thank Karl Siebert and John Barnard for statistical consultations, Imelda Ryona for technical assistance, and Anthony Road Wine Company, Anyela's Vineyards, Bedell Cellars, Fox Run Vineyards, Hazlitt 1852 Vineyards, Mike Jordan, Raphael Winery, Shalestone Vineyards, and Vetter Vineyards for cooperation on this project.

Supplemental data is freely available with the online version of this article at www.ajevonline.org.

Manuscript submitted Jan 2011, revised Jul 2011, accepted Sept 2011. Publication costs of this article defrayed in part by page fees.

Copyright (C) 2012 by the American Society for Enology and Viticulture. All rights reserved.

doi: 10.5344/ajev.2011.11002 reported (Allen et al. 1991, Roujou de Boubée et al. 2000), although the relationship is less clear for concentrations around threshold (Preston et al. 2008). Because the herbaceous aromas associated with MPs are generally undesirable in red wine, there has been interest in developing management strategies to control MP levels. In mature grape berries, most ( $>95 \%$ ) IBMP is located in the grape skins at harvest (Roujou de Boubée et al. 2002) and 67\% $\pm 13 \%$ is extracted with conventional red winemaking practices (Ryona et al. 2009). Thus, the concentration in finished red wine is largely dependent on the concentration in grapes at harvest. Since current remediation techniques to remove MPs from musts or wine are either ineffective or result in other nonselective changes (Pickering et al. 2006), MPs are most effectively controlled with viticultural practices that reduce their content in grapes (Bogart and Bisson 2006).

IBMP accumulates from fruit set until $\sim 0$ to 14 days prior to veraison (Roujou de Boubée et al. 2002, Ryona et al. 2008). During fruit maturation, MPs rapidly degrade to concentrations $<10 \%$ of their preveraison peak values. Preveraison IBMP concentrations correlate strongly to IBMP concentrations at harvest within the same growing region (Ryona et al. 2008).

Several viticultural and environmental parameters are reported to correlate with MPs. In general, grapes and wines produced in cool regions and in cooler years are reported to have higher MP concentrations (Allen et al. 1994, Falcão et al. 2007). Higher temperatures during the ripening period are thought to enhance MP degradation, leading to lower concentrations at harvest (Lacey et al. 1991). Several groups have reported that cluster light exposure can reduce MPs at harvest (Marais et al. 1999, Ryona et al. 2008). Exposed 
clusters accumulate less IBMP than shaded clusters, and proportional differences persist until harvest. In contrast, cluster exposure does not influence the rate of postveraison degradation (Ryona et al. 2008). Consequently, management practices that improve cluster exposure (e.g., leaf removal) can reduce IBMP when imposed preveraison, but postveraison treatments are less effective (Scheiner et al. 2010). Conditions that stimulate vine vigor, such as high water availability and low bud numbers, are associated with high MP concentrations (Chapman et al. 2004, Sala et al. 2005), although the mechanism is unclear. Higher preveraison IBMP concentrations have been observed at more vigorous sites in California (Noble et al. 1995), and vine growth during the ripening period, induced by high rainfall, was reported to result in higher IBMP concentrations in Bordeaux (Roujou de Boubée et al. 2002). In Cabernet franc grown in a cool climate, higher IBMP concentrations were observed in vigorous vines with similar cluster exposures to vines of lower vigor, suggesting that vine vigor and cluster light exposure may independently influence MPs (Ryona et al. 2008).

In summary, cluster light exposure, temperature, fruit maturity, and conditions associated with vine vigor are linked to MPs, but it is unclear if the observed effects occur independently or indirectly. Studies have quantified MPs in fruit only at harvest or in wine, so it is not possible to determine if the observed differences were a function of changes in MP accumulation or of degradation. The objective of this study was to conduct a multivariate analysis to evaluate the correlation among viticultural variables, vine physiology, and mesoand microclimate and IBMP concentrations in Cabernet franc grape berries at preveraison and harvest.

\section{Materials and Methods}

Experimental design. Ten and eight commercial Cabernet franc vineyards in New York State were used for this study in 2008 and 2009, respectively (Table 1). At each site, two 5-vine panels were selected for data collection and sampling based on uniform vine age within each vine panel. Panels were selected with the intent of capturing a wide range of soil types, clones, and other variables in order to maximize the range in MPs among all sites. Measurement and sampling were performed on individual vines within each panel. Vine management was performed by the cooperating growers according to the regionally appropriate viticultural practices for $V$. vinifera in each respective area.

Vine/canopy characterization. The number of count and noncount shoots was recorded at anthesis and 50 days after anthesis (50 DAA), and shoot density was determined by dividing the number of total shoots per vine by in-row vine spacing. On divided canopy systems (i.e., Scott Henry), shoot density was determined by dividing the number of total shoots per vine by twice the in-row spacing. At anthesis, shoot length and number of nodes per shoot were measured from node 1 to the shoot tip on 20 randomly selected shoots per vine. Average internode length was determined by dividing the average shoot length by the number of nodes. Enhanced point quadrat analysis (EPQA) was conducted at $10 \mathrm{~cm}$ intervals in the fruiting zone at anthesis, 30 DAA, 50 DAA, and harvest (Meyers and Heuvel 2008). On training systems with multiple fruiting zones (i.e., Scott Henry, two-tier flatbow), insertions were made along each tier. In 2009, EPQA was also performed at $30 \mathrm{~cm}$ above the fruiting zone (midcanopy) at 50 DAA and harvest. Photosynthetically

Table 1 Location of Cabernet franc vineyards (sites) and characteristics for 5-vine panels used in the multivariate study.

\begin{tabular}{|c|c|c|c|c|c|c|c|c|}
\hline Site & Panel & Am. viticultural area & Clone & Rootstock & $\begin{array}{l}\text { Spacing } \\
\text { (m/row } x \\
\text { m/vine) }\end{array}$ & Training system ${ }^{a}$ & $\begin{array}{c}\text { Vineyard } \\
\text { age }^{\mathrm{b}}\end{array}$ & $\begin{array}{c}\text { Soil } \\
\text { series }^{c}\end{array}$ \\
\hline 1 & 1 & Finger Lakes & unknown & $3309 \mathrm{C}$ & $2.7 \times 1.6$ & Two-tier flatbow VSP & 7 & Aurora \\
\hline 1 & 2 & Finger Lakes & unknown & $3309 \mathrm{C}$ & $2.7 \times 1.6$ & Two-tier flatbow VSP & 7 & Aurora \\
\hline 2 & 1 & Finger Lakes, Seneca Lake & 1 & $3309 \mathrm{C}$ & $2.7 \times 1.8$ & Two-tier flatbow VSP & 13 & Cayuga \\
\hline 2 & 2 & Finger Lakes, Seneca Lake & 1 & $3309 \mathrm{C}$ & $2.7 \times 1.8$ & Two-tier flatbow VSP & 11 & Honeoye \\
\hline 3 & 1 & Finger Lakes, Seneca Lake & 1 & $\mathrm{SO} 4$ & $2.7 \times 1.7$ & Two-tier flatbow VSP & $>15$ & Cayuga \\
\hline 3 & 2 & Finger Lakes, Seneca Lake & 1 & $\mathrm{SO} 4$ & $2.7 \times 1.7$ & Two-tier flatbow VSP & $>15$ & Cayuga \\
\hline 4 & 1 & Finger Lakes, Seneca Lake & 1 & $\mathrm{SO} 4$ & $3.0 \times 2.2$ & Cordon spur/flat cane SH VSP & 6 & Howard \\
\hline 4 & 2 & Finger Lakes, Seneca Lake & 1 & $\mathrm{SO} 4$ & $3.0 \times 2.2$ & Cordon spur/flat cane SH VSP & 6 & Howard \\
\hline 5 & 1 & Finger Lakes, Seneca Lake & 214 & $\mathrm{SO} 4$ & $3.0 \times 2.2$ & Cordon spur/flat cane SH VSP & 9 & Howard \\
\hline 5 & 2 & Finger Lakes, Seneca Lake & 214 & $\mathrm{SO} 4$ & $3.0 \times 2.2$ & Cordon spur/flat cane SH VSP & 9 & Howard \\
\hline 6 & 1 & Finger Lakes, Seneca Lake & unknown & $3309 \mathrm{C}$ & $2.7 \times 1.7$ & Cordon spur SH VSP & 22 & Honeoye \\
\hline 6 & 2 & Finger Lakes, Seneca Lake & unknown & $3309 C$ & $2.7 \times 1.7$ & Cordon spur VSP & 15 & Aurora \\
\hline 7 & 1 & Long Island, North Fork & 1 & unknown & $2.7 \times 1.8$ & Cordon spur/flat cane VSP & 12 & Haven \\
\hline 7 & 2 & Long Island, North Fork & 332 & unknown & $2.7 \times 1.5$ & Cordon spur/flat cane VSP & 12 & Haven \\
\hline 8 & 1 & Long Island, North Fork & 1 & $3309 C$ & $2.7 \times 1.9$ & Cordon spur VSP & 7 & Haven \\
\hline 8 & 2 & Long Island, North Fork & 1 & $\mathrm{SO} 4$ & $2.7 \times 1.9$ & Cordon spur VSP & 7 & Haven \\
\hline 9 & 1 & Lake Erie & unknown & 3309C & $2.7 \times 1.4$ & Two-tier flatbow VSP & 5 & Chenango \\
\hline 9 & 2 & Lake Erie & unknown & 3309C & $2.7 \times 1.4$ & Two-tier flatbow VSP & 5 & Chenango \\
\hline 10 & 1 & Lake Erie & 327 & 3309C & $2.7 \times 1.9$ & Cordon spur & 8 & Hornell \\
\hline 10 & 2 & Lake Erie & 327 & $3309 \mathrm{C}$ & $2.7 \times 1.9$ & Cordon spur & 8 & Hornell \\
\hline
\end{tabular}

aVSP: vertical shoot-positioning; SH: Scott Henry.

${ }^{b}$ Age determined as years from planting in 2008; site 3 age unknown.

cSoil Survey Staff, USDA [http://soils.usda.gov/technical/classification/osd/index.html]. 
active radiation (PAR, 400-700 $\mathrm{nm}$ ) was measured in the fruiting zone with an AccuPAR LP-80 ceptometer (Decagon Devices, Cambridge, UK) on cloudless days between 10:30 and 15:00 hr. The probe was inserted parallel to the row in the interior of the canopy at the fruiting zone and midcanopy, and the average of four readings was recorded. At $50 \mathrm{DAA}$ and harvest, shoot diameters were measured midway between nodes 1 and 2 on 20 randomly selected shoots per vine with a Storm 3C301 Electronic Digital Caliper (Central Tools, Cranston, RI). At harvest, the number of nodes of ripe periderm was counted on 20 randomly selected shoots per vine.

Climatic measurements. PAR, rainfall, and air temperature were monitored from 1 May through harvest with Hobo Micro Station Data Loggers (Onset Computer Corp., Bourne, MA) placed in each vineyard within 50 meters of an experimental vine panel. PAR, rainfall, and temperature were measured each minute, and 5-min averages were logged. Growing degree days (GDD) were determined as GDD $=[$ (maximum daily temperature + minimum daily temperature) / 2] - 10 from 1 May to harvest, where temperatures were expressed in Celsius. PAR was not measured in May and June in 2008.

Sampling and harvest parameters. Fifty-berry samples at 30 and 50 DAA and 200-berry samples at harvest were collected at random from each vine for chemical analyses, including IBMP quantification (sampling dates listed in Supplemental Table 1). Sites in regions outside the Finger Lakes were not visited as frequently due to travel distance; therefore slight discrepancies may exist between actual and reported phenological stages. The berry samples were placed in storage bags, immediately frozen with liquid $\mathrm{N}_{2}$, and stored at $-23^{\circ} \mathrm{C}$ until analyses were performed.

At each site, harvest date was determined by the respective winery, and sample harvest occurred within three days of commercial harvest. Yield per vine was measured with a hanging scale accurate to $0.01 \mathrm{~kg}$ (model SA3N340; Salter Brecknell, Fairmont, MN) and cluster counts were recorded. Average cluster weight was calculated as yield divided by cluster count. Average fresh berry weight was determined by weighing the 200-berry harvest samples with a Setra SI410S balance (Setra Systems Inc., Boxborough, MA). In 2008, percent berry dry weight was calculated at harvest on a 50-berry subsample by grinding at 1600 strokes/min for 2 min using a 2000 Geno/Grinder (SPEX Certiprep, Metuchen, NJ), and drying a $20 \mathrm{~g}$ subsample in a drying oven at $60^{\circ} \mathrm{C}$ for 48 hr. Percent dry berry weight was calculated by dividing the initial subsample wet weight by the final dried weight. The remainder of the 200-berry sample was used for carbon isotope composition $\left(\delta^{13} \mathrm{C}\right)$ analysis and IBMP quantification. In 2009, average fresh berry weight was additionally determined at 30 and 50 days after anthesis using the 50-berry samples. During the winter, vines were pruned according to grower specifications and dormant cane pruning weight was recorded. Crop load was calculated as yield divided by pruning weight, and average cane weight was determined as total pruning weight divided by the number of canes.

Berry analysis for Brix, titratable acidity, and pH. A subsample of 150 frozen mature berries was placed in a 250
$\mathrm{mL}$ beaker and heated to $65^{\circ} \mathrm{C}$ for $1 \mathrm{hr}$ in a water bath to redissolve bitartrate crystals, pressed through cheesecloth with a pestle, and the juice was collected for analyses. Soluble solids (Brix) were measured using a digital refractometer (model 300017; SPER Scientific, Scottsdale, AZ) with temperature correction. Titratable acidity (TA) and $\mathrm{pH}$ were measured with an automatic titrater (Titrino model 798, Metrohm, Riverview, FL), and TA was measured with a $5.0 \mathrm{~mL}$ aliquot of juice by titration against $0.1 \mathrm{~N} \mathrm{NaOH}$ to $\mathrm{pH} 8.2$ and expressed as tartaric acid equivalents.

Berry and leaf analysis for carbon isotope composition. Carbon isotope composition $\left(\delta^{13} \mathrm{C}\right)$ analysis was performed on $10 \mathrm{~g}$ subsamples of berries collected at 50 DAA and harvest and on three sun-exposed leaves collected at 50 DAA and harvest from nodes 15,16 , and 17 from three randomly selected count shoots. Leaf and berry samples were dried in a drying oven at $60^{\circ} \mathrm{C}$ over a 48 -hr period and ground with a coffee grinder into a fine homogenous powder. $\delta^{13} \mathrm{C}$ analysis was performed using a Finnigan MAT Delta Plus (Bremen, Germany) isotope ratio mass spectrometer interfaced to a Carlo Erba NC2500 elemental analyzer and expressed as $\delta^{13} \mathrm{C}=\left[\left(\mathrm{R}_{\mathrm{s}}\right.\right.$ $\mathrm{R}_{\mathrm{pdb}}$ ) / $\left.\mathrm{R}_{\mathrm{pdb}}\right] \times 1000$, where $\mathrm{R}_{\mathrm{s}}={ }^{13} \mathrm{C} /{ }^{12} \mathrm{C}$ ratio of the sample and $\mathrm{R}_{\mathrm{pdb}}={ }^{13} \mathrm{C} /{ }^{12} \mathrm{C}$ ratio of the Pee Dee Belemnite) standard.

Berry analysis of IBMP. 3-Isobutyl-2-methoxypyrazine analysis was conducted on 50-berry samples collected at 30 DAA, 50 DAA, and harvest. The extraction method was headspace solid-phase microextraction (HS-SPME) and quantification was performed by comprehensive two-dimensional gas chromatography time-of-flight mass spectrometry (GCxGCTOF-MS), described in detail elsewhere (Ryona et al. 2009).

Fermentations. Fruit from each experimental plot (i.e., 5 -vine panel) was pooled for fermentation. Grapes were destemmed, crushed, and separated into 7.6 L fermentation vessels, with two fermentation replicates used per vine panel. Musts lower than 22 Brix were chaptalized to 22 Brix to simulate standard regional industry practices. $\mathrm{SO}_{2}(50 \mathrm{mg} / \mathrm{L})$ was added as potassium metabisulfite and musts were inoculated with Lalvin ICV GRE yeast (Lallemand, Santa Rosa $\mathrm{CA})$. Yeast nutrients were added as follows: GoFerm $(0.15$ $\mathrm{g} / \mathrm{L})$, Fermaid K (0.1 g/L), and diammonium hydrogen phosphate ( $1 \mathrm{~g} / \mathrm{L}$ DAP, $210 \mathrm{mg} / \mathrm{L}$ as $\mathrm{N})$. YAN was not measured in individual vine panels, but N.Y. State Cabernet franc is generally YAN deficient: the average in 2010 was $63 \pm 30 \mathrm{mg} / \mathrm{L}$ as $\mathrm{N}$ (http:/grapesandwine.cals.cornell.edu/cals/grapesandwine/ veraison-to-harvest/upload/Veraison-to-Harvest-2010-7.pdf), which necessitated the high DAP additions. Fermentations were carried out in a temperature controlled room at $20^{\circ} \mathrm{C}$. The musts were punched down twice a day until the end of alcoholic fermentation (four to six days). After the completion of alcoholic fermentation, an extended maceration was carried out for 5 days. Following extended maceration, wines were pressed through cheesecloth into $3.78 \mathrm{~L}$ carboys and inoculated for malolactic fermentation with Enoferm Alpha (Lallemand). At the end of malolactic fermentation, $60 \mathrm{mg} / \mathrm{L}$ $\mathrm{SO}_{2}$ was added to finished wines in the form of potassium metabisulfite, followed by cold stabilization at $2{ }^{\circ} \mathrm{C}$ for 60 days until bottling. 
Wine analysis for IBMP. At bottling, wine samples were collected for IBMP quantification by SPME extraction followed by GCxGC-TOF-MS. Five $\mathrm{mL}$ of wine was transferred into a $20 \mathrm{~mL}$ SPME vial and diluted with $5 \mathrm{~mL}$ Milli-Q water. $\mathrm{NaCl}(3 \mathrm{~g})$ was added to the vial followed by the $\left[{ }^{2} \mathrm{H}_{2}\right]$-IBMP internal standard at $10 \mathrm{pg} / \mathrm{mL}$. Parameters for SPME and GCxGC-TOF-MS were similar to those for whole berries, but with a SPME extraction temperature of $40^{\circ} \mathrm{C}$ and a desorption temperature of $250^{\circ} \mathrm{C}$.

Sensory evaluation. Ten experimental wines from each vintage, selected to represent the widest range in IBMP concentration, were evaluated for intensity of herbaceous and fruity aromas. A 10-member sensory panel consisting of eight females and two males, ages 24 to 48, analyzed the 2008 wines, and a nine-member sensory panel (same panelists as 2008) consisting of eight females and one male, ages 25 to 49 , analyzed the 2009 wines. Sensory panelists were selected based on interest and availability. Prior to the first session, sensory panelists were familiarized with the evaluation protocols and scorecard (anchored 9-point line scale). Aroma standards were provided to familiarize sensory panelists with a range of herbaceous and fruity aromas (Table 2). Multiple sensory standards were used to illustrate herbaceousness and fruitiness, since these terms refer to general categories of aromas and the intent was to avoid the assignment of an herbaceous perception to fruity because an appropriate standard was not presented. Panelists were not asked to determine the intensity of each attribute based on the individual sensory standards, as the panel was not trained to rate intensity because of time and cost constraints.

Following bottling, the 2008 vintage was stored at the N.Y. State Agricultural Experiment Station (NYSAES) wine cellar for eight months (March to October) at $12^{\circ} \mathrm{C}$ prior to testing, and sensory analysis was performed one year after harvest. For the 2009 vintage, sensory analysis needed to take place earlier because of time constraints, and wines were stored for 5 months following bottling (May to September) at a warmer temperature $\left(21^{\circ} \mathrm{C}\right)$ to compensate for the shorter storage time. Sensory evaluation was performed on 2009 wines 9 months after harvest. Twenty-four hours prior to testing, wines were moved to the testing area to equilibrate their temperature. Fifteen minutes prior to serving, $40 \mathrm{~mL}$ wine was poured

Table 2 Attributes and reference standards for 2008 and 2009 sensory panels for wines made from individual panels from sites 2-8 and 10 (2008) and sites 1-3 and 5-8 (2009).

\begin{tabular}{ll}
\hline Aroma attribute & Reference standard $^{\mathrm{a}}$ \\
\hline Herbaceous & $2 \mathrm{~g}$ bell pepper \\
Herbaceous & $5 \mathrm{~mL}$ juice from Great Value canned \\
& asparagus (Bentonville, AR) \\
Herbaceous & $5 \mathrm{~mL}$ juice from Great Value canned peas \\
Herbaceous & $15 \mu \mathrm{g} / \mathrm{L}$ IBMP \\
Herbaceous & $30 \mu \mathrm{g} / \mathrm{L}$ IBMP \\
Fruity & $2 \mathrm{~g} \mathrm{Smuckers} \mathrm{raspberry} \mathrm{jam} \mathrm{(Orrville,} \mathrm{OH)}$ \\
Fruity & $2 \mathrm{~g} \mathrm{Smuckers} \mathrm{blackberry} \mathrm{jam}$ \\
Fruity & $2 \mathrm{~g} \mathrm{Smuckers} \mathrm{strawberry} \mathrm{jam}$ \\
\hline
\end{tabular}

aStandards prepared in $40 \mathrm{~mL}$ Pinot noir base wine. into clear, $250 \mathrm{~mL}$ tulip-shaped glasses. Plastic covers were placed over the glasses to retain aromas. Sensory evaluation took place at the NYSAES sensory evaluation room under red lighting. Wines were evaluated for intensity of herbaceous and fruity aromas in triplicate using a randomized complete block design with order of presentation randomized within session. Five wine sets were presented, and sensory panelists were instructed to evaluate each wine separately from left to right. Sensory panelists waited $30 \mathrm{~min}$ and were then presented another set of five wines. Each panelist completed three sessions over a 3-week period.

Statistical analysis. Partial least squares regression (PLSR) was conducted with Minitab 15.0 statistical software (Minitab, Reading, MA) to model IBMP concentrations in grapes harvested from the individual vines. For model building, all x variables (122 in 2008 and 140 in 2009; Table 3) were used to create an initial model of IBMP in grapes from individual vines (100 vine samples in 2008; 80 vine samples in 2009). Data were normalized and the number of latent variables in each model was determined by the lowest predicted residual sum of squares (PRESS). Leave one out crossvalidation was used to calculate $p$ values and cross-validated regression coefficients, $Q^{2}$ (Brereton 2007). X variables that did not contribute to the model were removed manually by the forward selection process (Andersen and Bro 2010). The $\mathrm{x}$ variable with the lowest regression coefficient was removed and the model regenerated. The process was repeated until no further improvement in PRESS was observed. PLSR was implemented in a similar manner to model the intensity of herbaceous and fruit wine aroma. In this case, vine panel averages were used for viticultural and climatic measurements. One-way analysis of variance (ANOVA) and Welch's $t$-test were conducted using SPSS 19.0 statistical software (SPSS Inc., Chicago, IL). Means were separated using Games-Howell test at the $5 \%$ significance level. Wine sensory data were subjected to the mixed models procedure in SAS (SAS Institute Inc., Cary, NC), with judge treated as a random effect, and means were separated using the Tukey-Kramer procedure at the 5\% significance level. Linear regression analysis was conducted using SAS (PROC REG).

\section{Results}

Basic juice chemistry and climactic parameters. Rainfall, mean average maximum temperature, and accumulated GDDs differed among sites over each season, with greater variation in climate generally existing among regions rather than among sites within a region (Supplemental Table 2). The two years differed significantly in GDD, with 2008 (mean GDD, 1458) warmer than 2009 (mean GDD, 1342) at the sites measured in both years ( $p<0.05$ by paired $t$-test). Mean values for basic juice chemistry (Brix, $\mathrm{pH}, \mathrm{TA}$ ) are reported in Supplemental Table 3.

IBMP concentrations in Cabernet franc berries. There were significant differences $(p<0.001)$ in IBMP concentration across sites at all phenological stages (30 DAA, 50 DAA, and harvest) in 2008 and 2009 (Table 4). In 2008 and 2009, IBMP concentrations increased at nine of 10 sites and 
Table 3 X variables (measurements) included in initial 2008 and 2009 PLSR models to predict IBMP concentration at 50 DAA and log percent decrease in IBMP from 50 DAA to harvest.

\begin{tabular}{|c|c|c|c|c|}
\hline \multicolumn{2}{|r|}{ Vine } & \multirow{2}{*}{$\begin{array}{l}\text { Crop }^{c} \\
\text { Metric }\end{array}$} & \multicolumn{2}{|r|}{ Climate } \\
\hline Metric $^{a}$ & Phenology ${ }^{b}$ & & Metric $^{d}$ & Phenology \\
\hline Shoots/vine & AN, 50 DAA & Yield & Rainfall & $\begin{array}{l}\text { May, Jun, Jul, Aug, Sep, } 1 \text { Oct-HAR, } 1 \text { May-50 DAA, } \\
\text { AN-50 DAA, } 50 \text { DAA-HAR, } 65 \text { DAA-HAR, } 1 \text { May-HAR }\end{array}$ \\
\hline Shoots/meter & AN, 50 DAA & Cluster no. & Temp & $\begin{array}{l}\text { May, Jun, Jul, Aug, Sep, } 1-15 \text { Oct, } 1 \text { May- } 50 \text { DAA, } \\
\text { AN-50 DAA, } 50 \text { DAA-15 Oct, } 65 \text { DAA-15 Oct, } 1 \text { May- } \\
15 \text { Oct }\end{array}$ \\
\hline Shoot length & AN & Clusters/shoot & GDD & $\begin{array}{l}\text { May, Jun, Jul, Aug, Sep, } 1 \text { Oct-HAR, } 1 \text { May-50 DAA, } \\
\text { AN-50 DAA, } 50 \text { DAA-HAR, } 65 \text { DAA-HAR, } 1 \text { May-HAR }\end{array}$ \\
\hline Nodes/shoot & AN & Cluster wt & PAR & $\begin{array}{l}\text { May, Jun, Jul, Aug, Sep, } 1 \text { Oct-HAR, } 1 \text { May-50 DAA, } \\
\text { AN-50 DAA, } 50 \text { DAA-HAR, } 65 \text { DAA-HAR, } 1 \text { May-HAR }\end{array}$ \\
\hline Internode length & AN & Berry fresh wt & & \\
\hline Shoot diam. & 50 DAA, HAR & Percent berry dry wt & & \\
\hline$\delta^{13} \mathrm{C}$ berries & 50 DAA, HAR & Pruning wt & & \\
\hline$\delta^{13} \mathrm{C}$ leaves & 50 DAA, HAR & Average cane wt & & \\
\hline LLN & AN, 30 DAA, 50 DAA, HAR & Crop load & & \\
\hline PIL & AN, 30 DAA, 50 DAA, HAR & Yield/shoot & & \\
\hline PIC & AN, 30 DAA, 50 DAA, HAR & Soluble solids (TSS) & & \\
\hline$P G$ & AN, 30 DAA, 50 DAA, HAR & Titratable acidity & & \\
\hline OLN & AN, 30 DAA, 50 DAA, HAR & $\mathrm{pH}$ & & \\
\hline CEL & AN, 30 DAA, 50 DAA, HAR & TSS/titratable acidity & & \\
\hline LEL & AN, 30 DAA, 50 DAA, HAR & $\mathrm{TSS}^{*} \mathrm{pH}^{2}$ & & \\
\hline EP1 & AN, 30 DAA, 50 DAA, HAR & & & \\
\hline CEFA & AN, 30 DAA, 50 DAA, HAR & & & \\
\hline CEFA* $^{*}$ & AN, 30 DAA, 50 DAA, HAR & & & \\
\hline LEFA & AN, 30 DAA, 50 DAA, HAR & & & \\
\hline LEFA $^{*}$ & AN, 30 DAA, 50 DAA, HAR & & & \\
\hline Periderm & HAR & & & \\
\hline
\end{tabular}

${ }^{a}$ Nodes per shoot and internode length measured in 2008 only. LLN: leaf layer number; PIL: percent interior leaves; PIC: percent interior clusters; PG: percent gaps; OLN: occlusion layer number; CEL: cluster exposure layer; LEL: leaf exposure layer; EP1: canopy calibration coefficient; CEFA: cluster exposure flux availability; CEFA*: CEFA computed using dynamic calibration model; LEFA: leaf exposure flux availability; LEFA*: LEFA computed using dynamic calibration model; periderm: nodes of ripe periderm. LLN, PIL, PG, OLN, LEL, EP1, LEFA, and LEFA* measured at $30 \mathrm{~cm}$ above the fruiting zone in 2009 at 50 DAA and harvest.

bMeasurement at each phenological stage entered as a separate independent variable in models; AN: anthesis; DAA: days after anthesis; HAR: harvest.

'Crop measurements taken at harvest; pruning conducted during winter dormancy; berry weight collected at 30 and 50 DAA and harvest in 2009. ${ }^{d}$ GDD: growing degree days; PAR: photosynthetically active radiation. PAR expressed as an accumulation of daily average; was not measured in May and June 2008.

at seven of eight sites from 30 DAA to 50 DAA by an average of 63 and $82 \%$, respectively. Oddly, IBMP decreased from 30 DAA to 50 DAA in 2009 at one vineyard (site 8) by an average of $72 \%$.

From 50 DAA to harvest, IBMP concentrations decreased at all sites by an average of 93 and $72 \%$ in 2008 and 2009 , respectively. Although IBMP was significantly lower at 50 DAA at all sites in 2009 compared to 2008, at harvest only sites 5 and 8 had significantly lower concentrations, and only site 1 had significantly higher concentrations. Across sites, IBMP concentrations in 2008 did not correlate with those in 2009 at any phenological stage (30 DAA, $\mathrm{R}^{2}=0.09 ; 50 \mathrm{DAA}$, $\mathrm{R}^{2}=0.01$; harvest, $\mathrm{R}^{2}=0.26$ ). Additionally, no correlation was observed within each year between 50 DAA and harvest IBMP ( $\mathrm{R}^{2}<0.1$ for both years) in contrast to a previous report (Ryona et al. 2008).

Multisite PLSR models for IBMP at 50 DAA. Statistically significant PLSR models $(p<0.05)$ were constructed for IBMP in both $2008\left(\mathrm{R}^{2}=0.71, \mathrm{R}^{2}\right.$ validation $\left.=0.68\right)$ and $2009\left(\mathrm{R}^{2}=0.45, \mathrm{R}^{2}\right.$ validation $\left.=0.37\right)$. IBMP concentration in berries at 50 DAA was best predicted by variables associated with vine vigor and water availability such as shoot diameter, pruning weight, average cane weight, shoot length, and $\delta^{13} \mathrm{C}$ of berries (Table 5). Notably, variables associated with vine vigor had positive correlation coefficients. In 2008, average temperature from anthesis to 50 DAA had a significant and positive regression coefficient, while in 2009, crop load had a significant and positive regression coefficient. Regression plots of predicted IBMP versus observed IBMP in 2008 and 2009 are shown (Figure 1). While the "all-sites" PLS model is appropriate for predicting IBMP within vines for some sites, there are other sites where the all-sites PLS model poorly explains differences within sites. Using 2008 data, when the predicted IBMP versus observed IBMP from the all-sites model is plotted for the 10 vines at each site individually (data not shown), we observed a significant correlation at half of the sites (sites 1, 2, 3, 7, and 9; $p<0.05$ ) and a nonsignificant correlation at the other sites. In 2009, there were no significant correlations between predicted IBMP versus observed IBMP at individual sites using data from the all-sites model. 
Table 4 Mean IBMP concentration (picograms per gram fresh fruit) in Cabernet franc berries at 30 and 50 days after anthesis (DAA) and harvest (HAR) for each site in 2008 and 2009. Mean and SD were calculated for the 10 vines sampled from each site, i.e. represent vine panel averages.

\begin{tabular}{|c|c|c|c|c|c|c|c|c|c|c|c|c|c|c|c|}
\hline \multirow[b]{2}{*}{ Site } & \multicolumn{6}{|c|}{2008} & \multicolumn{6}{|c|}{2009} & \multicolumn{3}{|c|}{$p$ value (year) } \\
\hline & 30 DAA & SD & 50 DAA & SD & HAR & SD & 30 DAA & SD & 50 DAA & SD & HAR & SD & 30 DAA & 50 DAA & HAR \\
\hline 1 & $61.5 \mathrm{~cd}^{\mathrm{a}}$ & 19.7 & $102.5 \mathrm{bc}$ & 24.7 & $4.5 d$ & 1.0 & $9.0 \mathrm{~d}$ & 2.1 & $29.2 c$ & 6.1 & $13.8 a$ & 6.7 & $<0.001$ & $<0.001$ & 0.002 \\
\hline 2 & $112.1 \mathrm{a}$ & 20.8 & $167.6 a$ & 37.2 & $7.6 \mathrm{bd}$ & 3.0 & $22.4 \mathrm{bc}$ & 5.5 & $35.4 \mathrm{c}$ & 8.2 & $6.4 a b$ & 1.7 & $<0.001$ & $<0.001$ & 0.293 \\
\hline 3 & $49.7 \mathrm{~cd}$ & 31.8 & $103.2 \mathrm{bc}$ & 31.8 & $11.8 \mathrm{ad}$ & 7.9 & $6.5 d$ & 3.0 & $17.4 d$ & 4.4 & $8.3 a b$ & 1.8 & 0.002 & $<0.001$ & 0.202 \\
\hline 4 & $86.6 a c$ & 26.4 & $107.6 \mathrm{~b}$ & 16.3 & $9.5 a c$ & 2.9 & $14.6 \mathrm{~cd}$ & 6.7 & $32.8 c$ & 4.7 & 7.9ab & 2.1 & $<0.001$ & $<0.001$ & 0.097 \\
\hline 5 & $100.4 a b$ & 19.3 & $104.3 \mathrm{bc}$ & 24.2 & $13.3 a b$ & 5.3 & $17.8 \mathrm{c}$ & 4.0 & $51.1 b$ & 7.6 & $8.8 a b$ & 4.3 & $<0.001$ & $<0.001$ & 0.050 \\
\hline 6 & $49.0 d$ & 15.6 & $107.4 \mathrm{bc}$ & 23.3 & $11.5 \mathrm{ab}$ & 3.1 & $32.7 a b$ & 8.7 & $60.1 b$ & 5.8 & $11.2 \mathrm{a}$ & 3.9 & 0.012 & $<0.001$ & 0.816 \\
\hline 7 & 101.0ab & 16.3 & $191.5 a$ & 48.1 & $5.6 \mathrm{~cd}$ & 4.4 & $33.8 a$ & 3.1 & $87.0 a$ & 5.9 & $10.2 a b$ & 6.0 & $<0.001$ & $<0.001$ & 0.078 \\
\hline 8 & $86.6 \mathrm{ac}$ & 26.4 & $238.5 a$ & 48.6 & $12.1 \mathrm{a}$ & 2.1 & $41.6 a$ & 6.1 & $11.8 d$ & 6.4 & $4.6 \mathrm{~b}$ & 2.7 & $<0.001$ & $<0.001$ & $<0.001$ \\
\hline 9 & $74.8 \mathrm{bd}$ & 20.0 & $108.4 \mathrm{bc}$ & 25.0 & $1.3 e$ & 0.7 & - & - & - & - & - & - & - & - & - \\
\hline 10 & - & - & $74.0 \mathrm{c}$ & 20.9 & $6.0 \mathrm{~cd}$ & 1.9 & - & - & - & - & - & - & - & - & - \\
\hline $\begin{array}{l}p \text { value } \\
\text { (site) }\end{array}$ & $<0.001$ & & $<0.001$ & & $<0.001$ & & $<0.001$ & & $<0.001$ & & 0.001 & & & & \\
\hline
\end{tabular}

aWithin a column, means followed by a different letter are significantly different $(p<0.05$, Games-Howell). - indicates not measured.

Table 5 Partial least squares regression models: basic statistics of the models and regression coefficients of $x$ variables for the best model for IBMP concentration at 50 DAA (y variable) in Cabernet franc berries at all sites in 2008 (100 vines) and 2009 (80 vines).

\begin{tabular}{lcc}
\hline & \multicolumn{2}{c}{ Model } \\
\cline { 2 - 3 } Variable $^{\mathrm{a}}$ & $\mathbf{2 0 0 8}$ & $\mathbf{2 0 0 9}$ \\
\hline Temp anthesis 50 DAA & 0.26 & - \\
Shoot diam 50 DAA & 0.23 & - \\
$\delta^{13}$ C berry 50 DAA & -0.16 & -0.62 \\
$\delta^{13}$ C leaf 50 DAA & $-\mathrm{b}$ & 0.58 \\
Shoot length & 0.24 & 0.39 \\
Pruning wt & 0.08 & - \\
Average cane wt & 0.11 & - \\
Crop load & - & 0.44 \\
NLV & 2 & 4 \\
RMSE & 32.0 & 16.2 \\
$\mathrm{R}^{2}$ (calibration) & 0.71 & 0.46 \\
RMSECV & 33.5 & 17.4 \\
$R^{2}$ (validation) & 0.68 & 0.37 \\
$p$ value & $<0.001$ & $<0.001$ \\
\hline
\end{tabular}

aDAA: days after anthesis; NLV: number of latent variables; RMSECV: root mean square error of cross-validation.

b- indicates variable not in the model.

Variation among sites was greater than variation within sites (Table 4), which weakens the ability of our all-sites model to consider the more subtle within-site variation.

The loadings on the latent variables used in the regression models are shown (Table 6) and plotted (Supplemental Figure 1). The first latent variable in all of the models was characterized by variables associated with vigor such as shoot diameter, shoot length, pruning weight, average cane weight, and rainfall in July; the second latent variable was characterized by $\delta^{13} \mathrm{C}$ of either the leaves or berries. Crop load and average berry weight loaded to the same latent variables as the previously mentioned variables associated with vine vigor.

Single-site PLSR models for IBMP at 50 DAA. The all-sites model did not always effectively model differences within sites. Constructing PLSR models for each individual
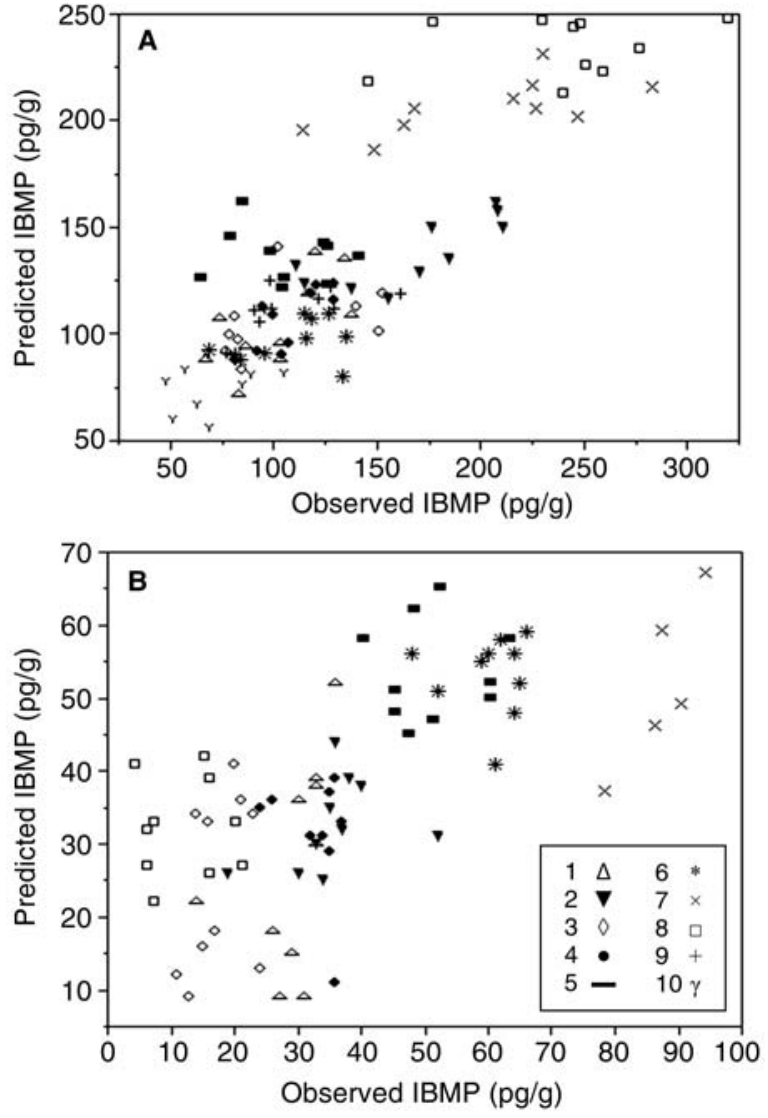

Figure 1 Plot of predicted vs. observed IBMP from the $(A) 2008\left(R^{2}=\right.$ $0.71)$ and $(B) 2009\left(R^{2}=0.45\right)$ all-sites models described in Table 5. Each point represents an individual vine, and different symbols represent different vineyard sites. Sites 9 and 10 were not used in 2009.

site eliminated variables associated with local climate and allowed for an in-depth evaluation of variability in berry IBMP concentration within individual sites. In 2008 and 2009, single-site models were constructed for all 10 and 8 sites, respectively. Although the PLSR models were significant for all single sites $(p<0.05)$, the predictive quality of 
the 2008 models was poor $\left(\mathrm{R}^{2}\right.$ validation range $=0.11$ to 0.64 , average $\mathrm{R}^{2}$ validation $\left.=0.356\right)$. In contrast, the 2009 singlesite models constructed for IBMP concentration at 50 DAA had a higher predictive power than even the multisite models. The $\mathrm{R}^{2}$ validation of the 2009 single-site models ranged from 0.29 to 0.93 and averaged 0.66 . For each model, the signs of the regression coefficients of variables that contributed to the model were tabulated for each variable category: "vigor" included measurements of vine growth and $\delta^{13} \mathrm{C}$ values; "maturity" included pH, TSS, TA, and related metrics; and "light exposure" included cluster exposure flux availability (CEFA) and other appropriate EPQA metrics (Figure 2). Similar to the multisite models, variables associated with vine vigor were included in 17 of 18 single-site models. At 15 of these sites, there were positive correlations between IBMP and vigor, versus two with negative correlations, a statistically significant difference $\left(p<0.05\right.$, chi-squared test). $\delta^{13} \mathrm{C}$ in the berries

Table 6 Partial least squares regression models: loadings of the $\mathrm{x}$ variables for the first two components for the IBMP concentration at 50 DAA models in 2008 and 2009.

\begin{tabular}{|c|c|c|c|c|}
\hline \multirow[b]{2}{*}{$X$ variable $^{a}$} & \multicolumn{2}{|c|}{$2008^{b}$} & \multicolumn{2}{|c|}{$2009^{b}$} \\
\hline & LV1 & LV2 & LV1 & LV2 \\
\hline Temp anthesis 50 DAA & 0.44 & 0.35 & - & - \\
\hline Shoot diam 50 DAA & 0.46 & 0.05 & - & - \\
\hline$\delta^{13} \mathrm{C}$ berry $50 \mathrm{DAA}$ & -0.13 & 0.55 & 0.30 & -1.17 \\
\hline$\delta^{13} \mathrm{C}$ leaf $50 \mathrm{DAA}$ & $-c$ & - & 0.72 & -0.21 \\
\hline Shoot length & 0.46 & 0.23 & 0.73 & 0.10 \\
\hline Pruning wt & 0.40 & -0.55 & - & - \\
\hline Average cane wt & 0.45 & -0.48 & - & - \\
\hline Rainfall July & - & - & - & - \\
\hline Berry wt 50 DAA & - & - & - & - \\
\hline Crop load & - & - & -0.19 & -0.06 \\
\hline Explained variance (\%) & 68.9 & 2.0 & 27.1 & 16.2 \\
\hline
\end{tabular}

aDAA: days after anthesis.

bLV: latent variable.

c- indicates variable not in the model.

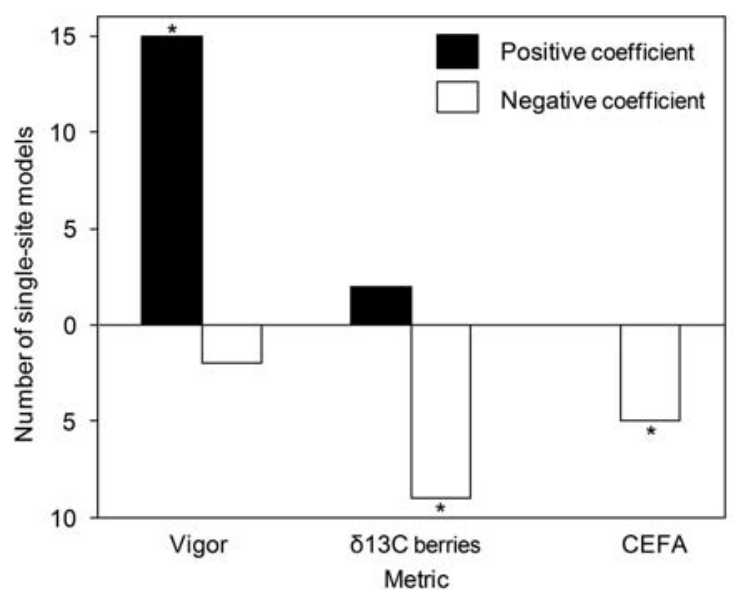

Figure 2 Sign of regression coefficients from single-site models for IBMP concentration at 50 days after anthesis in 2008 and 2009. Variable categories described in the Results text. * indicates that the distribution of signs for a variable category was significantly different from what was predicted by chance $(p<0.05$, chi-squared). was negatively correlated with IBMP accumulation at nine of these models, versus two with negative coefficients $(p<0.05)$. Although CEFA was not a predictor in the multisite models, it was negatively correlated with IBMP accumulation in five of the single-site models in 2008, and no models showed a positive correlation between cluster exposure and IBMP accumulation $(p<0.05)$. However, CEFA loaded on the same latent variables (data not shown) as the variables associated with vigor, indicating a correlation among the variables. In all 18 single-site models, the first latent variable was characterized by variables associated with vine vigor (data not shown).

Multisite PLSR models for log-fold decrease in IBMP, 50 DAA to harvest. Statistically significant models could be generated for the log-fold decrease in IBMP from 50 DAA to harvest, but the predictive power was weak (Supplemental Table 4). The $\mathrm{R}^{2}$ validation of the models was 0.29 and 0.10 in 2008 and 2009, respectively, considerably weaker than our models of IBMP accumulation. Shoot length loaded heavily on the first latent variables of both years (Supplemental Table 5) and was positively correlated with IBMP decrease (loading, 0.50 in 2008; 0.65 in 2009). Postveraison temperature also loaded heavily in 2008 (0.58), and shoot diameter at harvest loaded heavily in 2009 (0.51).

Single-site PLSR models for log-fold decrease in IBMP, 50 DAA to harvest. In comparison with the multisite models, the single-site models for log-fold decrease in IBMP concentration from 50 DAA to harvest had a higher predictive power. The range in $\mathrm{R}^{2}$ validation for the single-site models was 0.75 to 0.95 and 0.02 to 0.86 in 2008 and 2009, respectively, and the average $\mathrm{R}^{2}$ validation was 0.62 and 0.46 in 2008 and 2009, respectively. It was not possible to construct a satisfactory model to predict log-fold decrease in IBMP at sites 6 and $8\left(\mathrm{R}^{2}\right.$ validation $\left.<0.10\right)$. In all 16 of the satisfactory models, at least one measurement associated with vine vigor was included in the model (Figure 3). Specifically, in 12 of the models, $\delta^{13} \mathrm{C}$ of mature berries and crop to vine size were

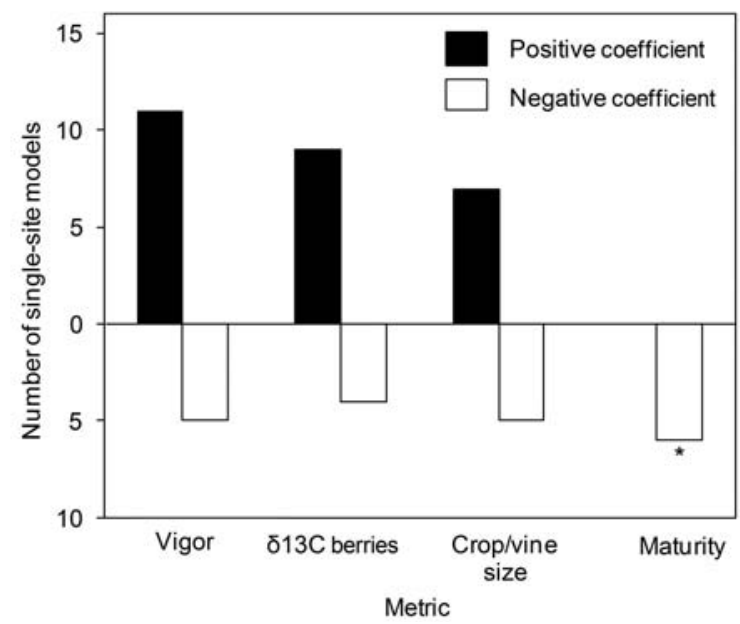

Figure 3 Sign of regression coefficients from single-site models for logfold decrease of IBMP from 50 days after anthesis to harvest in 2008 and 2009. Variable categories are described in Results text. * indicates that the distribution of signs for a variable category was significantly different from what was predicted by chance ( $p<0.05$, chi-squared). 
included. However, the relationship between log-fold decrease in IBMP and measurements associated with vine vigor, crop to vine size, and $\delta^{13} \mathrm{C}$ were site dependent and had both positive and negative regression coefficients. Measurements of fruit maturity were variables in six of the models and in all cases had positive regression coefficients.

Sensory evaluation of wines. IBMP concentrations in wines ranged from undetectable to $17 \mathrm{pg} / \mathrm{mL}$ (2008) and undetectable to $13 \mathrm{pg} / \mathrm{mL}$ (2009) (Supplemental Table 3). Because the mean reported values for IBMP in berries reported are not weighted based on the yield from each vine (Table 4 ), and because yield varied among sites, it was possible for wine IBMP to be greater than the mean grape IBMP across vines for a given panel. There was no correlation $\left(\mathrm{R}^{2}=0.03\right.$ and 0.02 ) between IBMP concentration and intensity of herbaceous aroma of wines in either year (Figure 4).

Significant differences were observed among the 2008 wines in the herbaceous aroma intensity and in the 2009 herbaceous and fruit aroma intensity (Supplemental Table 6). There was a significant sensory panelist $\mathrm{x}$ wine interaction for intensity of fruit aroma in the 2009 wines, indicating some inconsistency in panelist use of this descriptor. No other interaction terms were significant.

PLSR models for aroma intensity. PLSR models were constructed to predict the intensity of herbaceous aroma in the 2008 and 2009 wines and intensity of fruit aroma in the 2009 wines (Table 7). The $\mathrm{R}^{2}$ validation of the 2008 herbaceous, 2009 herbaceous, and 2009 fruit models were 0.76 , 0.73 , and 0.32 , respectively $(p<0.05)$. It was not possible to construct a satisfactory model to predict the intensity of fruit aroma in the 2008 wines. In the 2008 herbaceous model, $\delta^{13} \mathrm{C}$ of mature berries was the most important variable (regression coefficient $=0.76)$, followed by shoot length $(-0.57)$, Brix* $\mathrm{pH}^{2}$ $(-0.53)$, and $\mathrm{pH}(-0.29)$. In the 2009 herbaceous model, $\delta^{13} \mathrm{C}$ of mature berries and leaves at harvest had the highest regression coefficients (1.77 and -1.44 , respectively), and average cane weight had a negative correlation coefficient (-1.02). A plot of $\delta^{13} \mathrm{C}$ versus herbaceousness is shown (Figure 5).

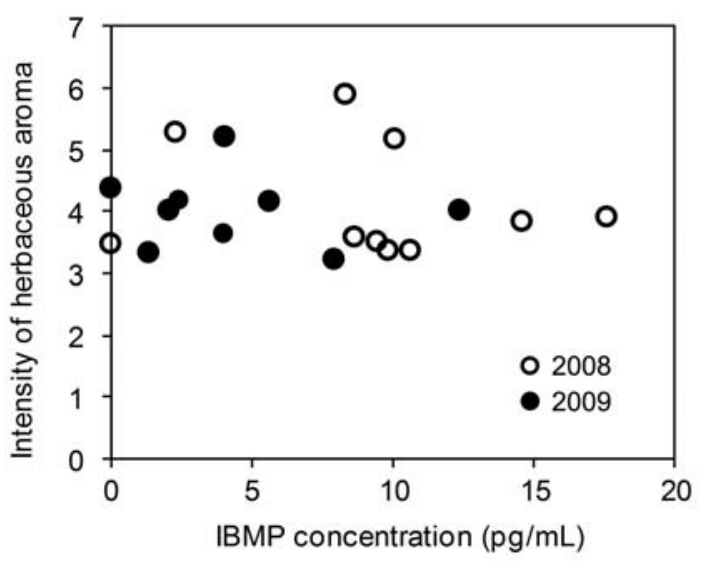

Figure 4 Linear regression of IBMP concentration and intensity of herbaceous aroma for 2008 and 2009 Cabernet franc wines. Coefficient of determination $=0.03(2008)$ and 0.02 (2009). No significant correlation was observed $(p>0.05)$.

\section{Discussion}

Grapes and wine produced in cool regions and cool years are reported to have higher IBMP concentrations (Allen et al. 1991, Falcão et al. 2007, Lacey et al. 1991), but we did not observe this phenomenon. In 2008 and 2009, the average growing degree accumulation $\left({ }^{\circ} \mathrm{C}\right)$ from 1 May to 50 DAA across sites was 894 and 799, respectively, and IBMP concentrations at 50 DAA were significantly higher $(69 \%)$ at all sites in 2008. In concordance with other studies (Hashizume and Umeda 1996, Lacey et al. 1991), the decrease in IBMP from 50 DAA to harvest was lower in the cooler year (2009), but concentrations at harvest were still significantly lower in 2009 than 2008 at two sites and not significantly different at five sites as a result of the reduced accumulation. We constructed

Table 7 Partial least squares regression models: basic statistics of the models and regression coefficients of $x$ variables for the best model for intensity of herbaceous and fruity aroma (y variable) for 2008 and 2009 wines.

\begin{tabular}{lccc}
\hline & \multicolumn{3}{c}{ Model } \\
\cline { 2 - 4 } Variable $^{\mathrm{a}}$ & $\begin{array}{c}\mathbf{2 0 0 8} \\
\text { herbaceous }\end{array}$ & $\begin{array}{c}\mathbf{2 0 0 9} \\
\text { herbaceous }\end{array}$ & $\begin{array}{c}\mathbf{2 0 0 9} \\
\text { fruit }\end{array}$ \\
\hline$\delta^{13} \mathrm{C}$ berry HAR & 0.76 & 1.77 & 0.67 \\
$\delta^{13} \mathrm{C}$ leaf HAR & $-\mathrm{b}$ & -1.44 & - \\
Shoot length & -0.57 & - & 0.16 \\
LLN anthesis & - & - & 0.66 \\
Periderm & - & - & -0.80 \\
Avg cane wt & - & -1.02 & - \\
Brix ${ }^{*} \mathrm{pH}^{2}$ & -0.53 & - & - \\
$\mathrm{pH}$ & -0.29 & - & - \\
$\mathrm{NLV}$ & 2 & 3 & 2 \\
$\mathrm{RMSE}$ & 0.10 & 0.10 & 0.24 \\
$\mathrm{R}^{2}$ (calibration) & 0.92 & 0.88 & 0.72 \\
$\mathrm{RMSECV}$ & 0.32 & 0.20 & 0.60 \\
$\mathrm{R}^{2}$ (validation) & 0.76 & 0.73 & 0.32 \\
$p$ value & 0.002 & 0.026 & 0.044 \\
\hline
\end{tabular}

aHAR: harvest; LLN: leaf layer number; NLV: number of latent variables; RMSECV: root mean square error of cross-validation.

b_ indicates variable not in the model.

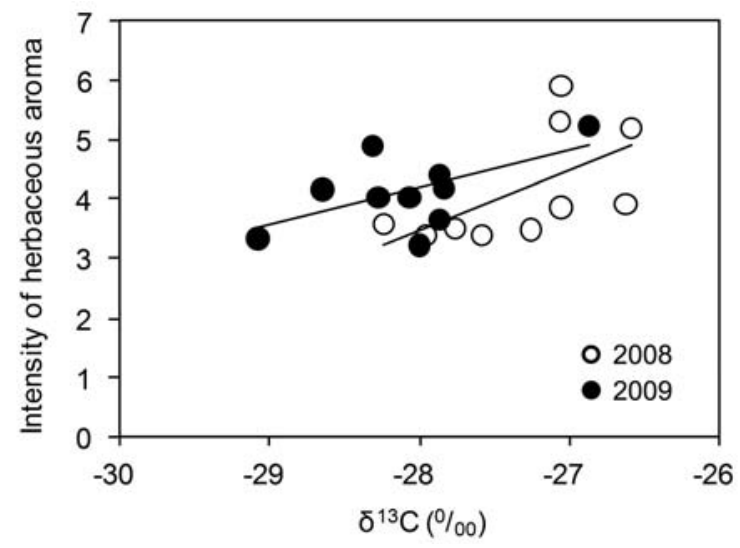

Figure 5 Correlation between $\delta^{13} \mathrm{C}$ in berries at harvest and intensity of herbaceous aroma for 2008 and 2009 Cabernet franc wines. Coefficient of determination $=0.35(2008)$ and $0.32(2009)$. Regression equation $=$ $-0.99 x+31.34(2008)$ and $-0.61 x+21.25$ (2009). The correlation was significant in both years $(p<0.05)$. 
PLSR models, combining all sites and years to predict IBMP at 50 DAA and log-fold decrease in IBMP from 50 DAA to harvest (data not shown), and temperature was an important predictor in both models. Average temperature from anthesis to 50 DAA positively correlated with IBMP concentration at 50 DAA, and average temperature from 50 DAA to harvest positively correlated with the log-fold decrease in IBMP, suggesting that both pre- and postveraison temperatures are important determinants of final IBMP concentrations. Earlier studies cited above have focused on temperature during the ripening period and quantified IBMP after the onset of degradation, but did not address the impact of temperature on IBMP accumulation.

There was significant variation within and among sites in IBMP concentrations at both preveraison time points and harvest, but the site-to-site variation was greater (Table 3). The PLSR models indicated that IBMP accumulation was predicted by variables associated with vine vigor. In general, vines with higher vigor reflected in greater shoot length and diameter, cane weight, and other associated variables accumulated more IBMP. The most frequently used variable in 50 DAA models was the berry carbon isotope ratio. The carbon isotope ratio $\left(\delta^{13} \mathrm{C}\right)$ of grape leaves and berries correlates with predawn leaf water potential and is an indicator of vine water status (de Souza et al. 2003). In response to stress (e.g., drought), the stomatal aperture decreases, resulting in depletion of ${ }^{12} \mathrm{C}$ and less discrimination against the heavier carbon isotope, ${ }^{13} \mathrm{C}$, resulting in an increase in $\delta^{13} \mathrm{C}$. Berry $\delta^{13} \mathrm{C}$ was a better predictor of IBMP concentration at 50 DAA than leaf $\delta^{13} \mathrm{C}$. Interestingly, leaf $\delta^{13} \mathrm{C}$ had an opposite regression coefficient of berry $\delta^{13} \mathrm{C}$ in several of the models. Because we only sampled sun-exposed leaves from nodes 15,16 , and 17 , it is likely that berry $\delta^{13} \mathrm{C}$ was a better representation of the whole canopy over berry development. In all but two of the models for IBMP at 50 DAA, berry $\delta^{13} \mathrm{C}$ was negatively correlated with IBMP. Thus, vines with higher discrimination (i.e., less water stress) tended to be more vigorous and have fruit with higher IBMP concentrations. However, in the multisite models, $\delta^{13} \mathrm{C}$ loaded heavily on a different latent variable than the variables associated with vine vigor. This discrepancy could potentially be explained by other variables that influence vigor, including bud number, nutrient availability, rootstock, and crop level.

It is not entirely clear why MP accumulation should be linked to temperature or to water availability. Several metabolic processes in grapes, such as photosynthesis, are known to increase with increasing temperature to a point before decreasing (Keller 2010). However, only a single enzyme family associated with MP biosynthesis has been identified: two $O$-methyltransferases ( $V v O M T 1 / 2)$ responsible for methylation of hydroxypyrazine (HP) intermediates (Dunlevy et al. 2010). To our knowledge, the temperature dependence of $V v O M T 1 / 2$ activity has not been characterized. A recent report has characterized another $V$. vinifera OMT responsible for methylation of flavonoids (FAOMT), which showed four-fold greater activity at $37^{\circ} \mathrm{C}$ than at $25^{\circ} \mathrm{C}$ and maximum activity at $50^{\circ} \mathrm{C}$ (Lücker et al. 2010). While this could potentially explain greater MP accumulation at high temperatures, it is possible that the other uncharacterized steps in hydroxypyrazine synthesis are also temperature sensitive.

Although variables associated with vine vigor explained the majority of variance in IBMP concentration at 50 DAA across and within sites in each year, vigor did not appear to correlate well with explaining differences in IBMP between years. In 2009, vines were significantly more vigorous, $p<$ 0.05 , (average cane weight across sites, $65.7 \pm 26 \mathrm{~g}$ ) than the previous year (average cane weight across sites, $=46.1 \pm 22$ g). The most noticeable difference between the two years was that 2008 had higher preveraison temperatures $(p<0.05$, Supplemental Table 2).

In field studies, preveraison cluster light exposure can reduce IBMP accumulation (Marais et al. 1999, Ryona et al. 2008). One exception, a reduction in IBMP accumulation in the absence of light, has been reported (Hashizume and Samuta 1999), but this experiment was performed on harvested unripe berries, and extrapolating these results to clusters still on the vine may not be appropriate. Cluster light exposure was not a predictor in any of the multisite models for IBMP concentration at $50 \mathrm{DAA}$. Because canopy management practices (e.g., leaf removal, shoot thinning, shoot positioning, hedging) were imposed by growers at different phenological stages and differing intensities across sites, it is possible that we did not capture the true dynamics of exposure during the preveraison period. Even with these caveats, the lack of predictive ability of cluster light exposure in the multisite study is not surprising; the differences in IBMP between fully shaded and fully exposed fruit within a vineyard do not usually exceed a factor of two (Marais et al. 1999, Ryona et al. 2008, Scheiner et al. 2010). However, the variation in IBMP among and within regions, including in our current study, is reported to exceed an order of magnitude (Allen et al. 1994, Ryona et al. 2008). Furthermore, in five of the single-site models for IBMP at 50 DAA, cluster light exposure, reported as cluster exposure flux availability (CEFA), was negatively correlated with IBMP but loaded to the same latent variables as the $\mathrm{x}$ variables associated with vigor. Thus, in all but one instance where CEFA contributed with a negative loading to a single-site model of IBMP accumulation, it was coincident with a positive loading from vigor metrics. By comparison, in 9 of the 15 single-site models where vigor metrics had positive loadings, CEFA had no contribution to the model. As previously observed, in contrast to vigor, CEFA was not useful in modeling IBMP accumulation in the multisite models. That may indicate that vine vigor independent of cluster exposure can have a greater influence than cluster exposure on IBMP accumulation, but better controlled experiments would be necessary to be conclusive.

In general, IBMP concentrations in Cabernet franc followed the expected pattern over the growing season of preveraison accumulation followed by postveraison degradation. However, in 2009, there was a $72 \%$ decrease in IBMP from 30 DAA to 50 DAA at one site (site 8), in contrast to several reports that IBMP peaks in concentration $\sim 0$ to 14 days before veraison (Roujou de Boubée et al. 2002, Ryona et al. 2008) 
as well as all other sites in our current studies. Because the results were highly anomalous, we confirmed the numbers by rerunning the samples, starting with berries, another two times. We also verified that peak shape and qualifier ion ratios were unaffected, indicating that interferences were unlikely. At site 8 , the 50 DAA samples were collected $\sim 10$ days before veraison, indicating that IBMP did decrease earlier than previously reported. The vines at site 8 were highly vigorous and thinned to less than one cluster per shoot (average yield/ pruning weight, 1.18, average clusters/shoot, 0.6 ) at $~ 20$ DAA, but we cannot establish that this practice led to an early decrease in IBMP. At harvest, Brix and TA were 21.6 and 7.3 $\mathrm{g} / \mathrm{L}$, values not indicative of advanced maturity.

In contrast to a previous report (Ryona et al. 2008), no correlation was observed between preveraison and harvest IBMP concentrations. In this previous work, the study was performed in a single region (Finger Lakes, NY), and soluble solids accumulation and the time elapsed between veraison and harvest were comparable among sites. It may be that preveraison IBMP is not a useful predictor of harvest IBMP across regions which differ in their rate of maturation. In comparison to IBMP accumulation, our attempts to model IBMP decrease across sites were less successful, as several $\mathrm{x}$ variables important to modeling IBMP decrease within a given site did not behave consistently from site to site. For example, variables associated with vine vigor were almost equally likely to have negative or positive correlations in our single-site models (Figure 3). Vine vigor measurements were taken before veraison, thus we cannot establish if they were an accurate representation of vine growth after veraison. However, all growers in our study reported using similar practices postveraison: no leaf removal was performed after veraison, but shoot tips were hedged at all sites. Therefore, practices should not have resulted in any systematic bias. We did observe that vines at some sites were still actively growing at harvest, and vine vigor has been reported to delay fruit maturity (Carbonneau 1997). Thus, the opposing relationship between these measurements and decrease in IBMP from site-to-site may have resulted from differences in fruit maturation as affected by vigor. In accordance, another group (Roujou de Boubée et al. 2000) tentatively correlated a decreased rate in IBMP degradation in Cabernet Sauvignon to late-season vine growth induced by high rainfall. It is also well established that overcropping can slow fruit maturation (Jackson and Lombard 1993). In 11 of the single-site models, measurements of crop to vine size (crop load, yield per shoot, clusters per shoot) were important predictors of IBMP decrease, but both positive and negative correlations were observed depending on the site. At three of the four sites where measurements of crop to vine size (crop load, yield per shoot, clusters per shoot) negatively correlated with log-fold decrease in IBMP, fruit maturity was positively correlated with log-fold decrease in IBMP, indicating that vines with higher crop to vine size had less mature fruit. Several groups have reported correlations between IBMP concentrations and fruit maturity indices such as Brix and malic acid (Chapman et al. 2004, Hashizume and Umeda 1996, Roujou de Boubée et al. 2002). Although neither IBMP at harvest nor the IBMP decrease could be predicted by Brix, $\mathrm{pH}$, and TA across multiple sites, similar to previous observations (Ryona et al. 2008), within a site the log-fold decrease in IBMP positively correlated with these simple maturity indices in six of the single-site models (Figure 3), a significant result ( $p<0.05$, chi-squared test).

In the wines vinified from the 5-vine panels at each site (20 in 2008 and 15 in 2009), IBMP concentrations were at or above the reported sensory detection threshold, $15 \mathrm{pg} / \mathrm{mL}$ (Roujou de Boubée et al. 2000) in only a single wine (Figure 4). We have seen similar results in other recent studies; for example, in 2007, >15 pg/mL IBMP in only two of 13 sites in the Finger Lakes (Ryona et al. 2008). The percentage of wines with IBMP exceeding $15 \mathrm{pg} / \mathrm{mL}$ is comparable to the percentage reported for warmer climates (Allen et al. 1994, Chapman et al. 2004), even though MP concentrations are reportedly higher in cool regions.

The concentration of IBMP in grapes was correlated with the IBMP concentration in wines in the individual vine panel vinifications $\left(\mathrm{R}^{2}=0.76, p<0.05\right.$, one-way ANOVA). IBMP concentrations in some wines were higher than the grapes from their corresponding panels (Supplemental Table 3) because the wines represent weighted averages of multiple vines. That also likely resulted in a weaker correlation coefficient than is reported elsewhere (Ryona et al. 2009).

The intensity of herbaceous aroma of the Cabernet franc wines was not linearly correlated with IBMP $(p>0.05$ in both years) (Figure 4 ). While a correlation between IBMP and herbaceousness has been reported in wines from New Zealand and Australia (Allen et al. 1991) and France (Roujou de Boubée et al. 2000), these studies included some wines with $>30 \mathrm{pg} / \mathrm{mL}$ IBMP, at least two-fold over its reported sensory threshold of $15 \mathrm{pg} / \mathrm{mL}$ (Roujou de Boubée et al. 2000). In our work, IBMP ranged from well below to just above the sensory detection threshold in red wine, suggesting that IBMP is not a useful proxy for herbaceousness in N.Y. Cabernet franc in the sites under study. Similar observations have been made for California Cabernet Sauvignon with comparable IBMP concentrations (Preston et al. 2008). Fruity aromas can mask the perception of herbaceous aromas, and vice versa (Hein et al. 2009), and we observed a similar inverse correlation between fruity and vegetal aromas in our work (Supplemental Figure 2). Thus, the difference in vegetal aroma intensity may relate to an absence of fruity aromas or the presence of other herbaceous odorants (e.g., $\mathrm{C}_{6}$ alcohols), as wines produced from grapes not known to produce significant levels of IBMP can also have herbaceous aromas (Guinard and Cliff 1987). As a caveat, the wines from the two studies were stored under different conditions following bottling $\left(9\right.$ months at $12^{\circ} \mathrm{C}$ for the 2008 vintage vs. 5 months at $21^{\circ} \mathrm{C}$ for the 2009 vintage), which could affect the relative rates of formation or loss of other odorants such as esters across the two years.

The intensity of herbaceous aroma was modeled using viticultural and climatic measurements, and the single most important predictor was the $\delta^{13} \mathrm{C}$ of mature berries. Related 
variables (shoot length and average cane weight) also negatively correlated with herbaceous aroma. Wines made from grapes with a lower vine water status and vigor indicated by greater $\delta^{13} \mathrm{C}$, shorter shoot length, and smaller cane weights were rated as having the highest intensity of herbaceous aromas (Figure 5). This observation is surprising, considering that lower water availability and reduced vine growth have been associated with less herbaceous aromas and with improved red wine quality in general (Jackson and Lombard 1993). However, many of these previous studies investigated systems with a wide range of water availabilities, either by natural causes or cultural practices (i.e., deficit irrigation). Here, the range of $\delta^{13} \mathrm{C}$ values within a year was $<2 \%$, less than reported elsewhere (de Souza et al. 2003). Additionally, all sites had $\delta^{13} \mathrm{C}$ $<-26 \%$, likely indicating similarly high water availability. The weaker predictive ability of water status for wine quality in years with higher water availability has been previously reported (Van Leeuwen 2010). In 2008, herbaceousness was also inversely correlated with classic maturity indices $(\mathrm{pH}$, $\mathrm{TSS}^{*} \mathrm{pH}^{2}$ ). The latter metric was originally suggested for use in predicting maturity in hot climates (Coombe et al. 1980). However, at least in one year, it appears to be appropriate for predicting IBMP degradation in a cool climate.

\section{Conclusion}

The general assertion that cooler growing conditions produce winegrapes with higher IBMP concentrations appears to be an oversimplification: here there was less IBMP accumulation in the cooler year of two, but the IBMP degradation rate from 50 DAA to harvest was also lower in this cooler season. As a result, IBMP concentrations at harvest were not significantly different between years at most sites, and their concentrations in grapes and wines were comparable to those reported in warmer regions. Within each year, IBMP concentrations at 50 DAA were best predicted by $\mathrm{x}$ variables associated with vine vigor, where vigorous vines accumulated higher IBMP preveraison. IBMP degradation postveraison was less successfully modeled, but was best predicted by variables associated with vine vigor, crop to vine size, and fruit maturity. The results of this study suggest that high IBMP concentrations at harvest are likely to occur at vigorous sites where warm preveraison temperatures are followed by inadequate fruit maturation. Also, variables that can model IBMP variation within a given site (e.g., cluster light exposure) are not necessarily important for explaining the majority of variation across sites. In contrast to some previous studies, IBMP concentrations in wines were not correlated with herbaceous aromas, likely because the highest IBMP concentrations present were around the sensory threshold. Herbaceous aroma intensity was inversely correlated not only with classic fruit maturity indices but also with higher water status and vigor, possibly because of the high water availability at all sites under study in both years. Finally, the poor correlation of IBMP and herbaceousness indicates that quantifying a broader range of volatiles in these wines will be necessary to better understand vegetal aromas and will be the subject of follow-up studies.

\section{Literature Cited}

Alberts, P., M.A. Stander, S.O. Paul, and A. De Villiers. 2009. Survey of 3-alkyl-2-methoxypyrazine content of South African Sauvignon blanc wines using a novel LC-APCI-MS/MS method. J. Agric. Food Chem. 57:9347-9355.

Allen, M.S., M.J. Lacey, and S. Boyd. 1994. Determination of methoxypyrazines in red wines by stable-isotope dilution gas-chromatography mass-spectrometry. J. Agric. Food Chem. 42:1734-1738.

Allen, M.S., M.J. Lacey, R.L.N. Harris, and W.V. Brown. 1991. Contribution of methoxypyrazines to Sauvignon blanc wine aroma. Am. J. Enol. Vitic. 42:109-112.

Andersen, C.M., and R. Bro. 2010. Variable selection in regression-A tutorial. J. Chemom. 24:728-737.

Bogart, K., and L. Bisson. 2006. Persistence of vegetal characters in winegrapes and wine. Prac. Winery Vineyard 86:13-20.

Brereton, R. G. 2007. Applied Chemometrics for Scientists. Wiley \& Sons, Chichester.

Carbonneau, A. 1997. General relationship within the whole-plant: Examples of the influence of vigour status, crop load and canopy exposure on the sink "berry maturation" for the grapevine. Acta Hort. 427:99-118.

Chapman, D.M., J.H. Thorngate, M.A. Matthews, J.X. Guinard, and S.E. Ebeler. 2004. Yield effects on 2-methoxy-3-isobutylpyrazine concentration in Cabernet Sauvignon using a solid phase microextraction gas chromatography/mass spectrometry method. J. Agric. Food Chem. 52:5431-5435.

Coombe, B.G., R.J. Dundon, and A.W.S. Short. 1980. Indexes of sugar-acidity as ripeness criteria for wine-grapes. J. Sci. Food Agric. 31:495-502.

De Souza, C.R., J.P. Maroco, T.P. Dos Santos, M.L. Rodrigues, C.M.Lopes, J.S. Pereira, and M.M. Chaves. 2003. Partial rootzone drying: Regulation of stomatal aperture and carbon assimilation in field-grown grapevines (Vitis vinifera cv. Moscatel). Funct. Plant Biol. 30:653-662.

Dunlevy, J.D., K.L. Soole, M.V. Perkins, E.G. Dennis, R.A. Keyzers, C.M. Kalua, and P.K. Boss. 2010. Two $O$-methyltransferases involved in the biosynthesis of methoxypyrazines: Grape-derived aroma compounds important to wine flavour. Plant Mol. Biol. 74:77-89.

Falcão, L.D., G. de Revel, M.C. Perello, A. Moutsiou, M.C. Zanus, and M.T. Bordignon-Luiz. 2007. A survey of seasonal temperatures and vineyard altitude influences on 2-methoxy-3-isobutylpyrazine, $\mathrm{C}_{13}$-norisoprenoids, and the sensory profile of Brazilian Cabernet Sauvignon wines. J. Agric. Food Chem. 55:3605-3612.

Guinard, J.X., and M. Cliff. 1987. Descriptive analysis of Pinot noir wines from Carneros, Napa, and Sonoma. Am. J. Enol. Vitic. $38: 211-215$

Hashizume, K., and T. Samuta. 1999. Grape maturity and light exposure affect berry methoxypyrazine concentration. Am. J. Enol. Vitic. 50:194-198

Hashizume, K., and N. Umeda. 1996. Methoxypyrazine content of Japanese red wines. Biosci. Biotechnol. Biochem. 60:802-805.

Hein, K., S.E. Ebeler, and H. Heymann. 2009. Perception of fruity and vegetative aromas in red wine. J. Sens. Stud. 24:441-455.

Jackson, D.I., and P.B. Lombard. 1993. Environmental and management practices affecting grape composition and wine quality - A review. Am. J. Enol. Vitic. 44:409-430.

Keller, M. 2010. The Science of Grapevines: Anatomy and Physiology. Academic Press/Elsevier, Burlington, MA.

Lacey, M.J., M.S. Allen, R.L.N. Harris, and W.V. Brown. 1991. Methoxypyrazines in Sauvignon blanc grapes and wines. Am. J. Enol. Vitic. 42:103-108. 
Lücker, J., S. Martens, and S.T. Lund. 2010. Characterization of a Vitis vinifera cv. Cabernet Sauvignon 3',5'-O-methyltransferase showing strong preference for anthocyanins and glycosylated flavonols. Phytochemistry 71:1474-1484.

Marais, J., J.J. Hunter, and P.D. Haasbroek. 1999. Effect of canopy microclimate, season and region on Sauvignon blanc grape composition and wine quality. S. Afr. J. Enol. Vitic. 20:19-30.

Meyers, J.M., and J.E. Vanden Heuvel. 2008. Enhancing the precision and spatial acuity of point quadrat analyses via calibrated exposure mapping. Am. J. Enol. Vitic. 59:425-431.

Noble, A.C., D.L. Elliott-Fisk, and M.S. Allen. 1995. Vegetative flavor and methoxypyrazines in Cabernet Sauvignon. In Fruit Flavors: Biogenesis, Characterization, and Authentication. R.L. Rouseff and M.M. Leahy (eds.), pp. 226-234. Am. Chemical Society, Washington DC.

Pickering, G., J. Lin, A. Reynolds, G. Soleas, and R. Riesen. 2006. The evaluation of remedial treatments for wine affected by Harmonia axyridis. Int. J. Food Sci. Technol. 41:77-86.

Preston, L.D., D.E. Block, H. Heymann, G. Soleas, A.C. Noble, and S.E. Ebeler. 2008. Defining vegetal aromas in Cabernet Sauvignon using sensory and chemical evaluations. Am. J. Enol. Vitic. 59:137-145.

Reynolds, A.G., and J.E. Vanden Heuvel. 2009. Influence of grapevine training systems on vine growth and fruit composition: A review. Am. J. Enol. Vitic. 60:251-268.

Roujou de Boubée, D., A.M. Cumsille, M. Pons, and D. Dubourdieu. 2002. Location of 2-methoxy-3-isobutylpyrazine in Cabernet Sauvi- gnon grape bunches and its extractability during vinification. Am. J. Enol. Vitic. 53:1-5.

Roujou de Boubée, D., C. Van Leeuwen, and D. Dubourdieu. 2000. Organoleptic impact of 2-methoxy-3-isobutylpyrazine on red Bordeaux and Loire wines. Effect of environmental conditions on concentrations in grapes during ripening. J. Agric. Food Chem. 48:4830-4834.

Ryona, I., B.S. Pan, D.S. Intrigliolo, A.N. Lakso, and G.L. Sacks. 2008. Effects of cluster light exposure on 3-isobutyl-2-methoxypyrazine accumulation and degradation patterns in red wine grapes (Vitis vinifera L. cv. Cabernet franc). J. Agric. Food Chem. 56:10838-10846.

Ryona, I., B.S. Pan, and G.L. Sacks. 2009. Rapid measurement of 3-alkyl-2-methoxypyrazine content of winegrapes to predict levels in resultant wines. J. Agric. Food Chem. 57:8250-8257.

Sala, C., O. Busto, J. Guasch, and F. Zamora. 2005. Contents of 3-alkyl-2-methoxypyrazines in musts and wines from Vitis vinifera variety Cabernet Sauvignon: Influence of irrigation and plantation density. J. Sci. Food Agric. 85:1131-1136.

Scheiner, J.J., G.L. Sacks, B. Pan, S. Ennahli, L. Tarlton, A. Wise, S.D. Lerch, and J.E. Vanden Heuvel. 2010. Impact of severity and timing of basal leaf removal on 3-isobutyl-2-methoxypyrazine concentrations in red winegrapes. Am. J. Enol. Vitic. 61:358-364.

Van Leeuwen, C. 2010. Terroir: The effect of the physical environment on vine growth, grape ripening and wine sensory attributes. In Managing Wine Quality. Vol. 1. Viticulture and Wine Quality. A.G. Reynolds (ed.), pp. 273-315. Woodhead Publishing, Cambridge, UK. 